\title{
Allometric deviations of plasma carotenoids in raptors
}

\author{
GUILLERMO BLANCO, ${ }^{1 *}$ LUIS M. BAUTISTA, ${ }^{1}$ DÁMASO HORNERO-MÉNDEZ, ${ }^{2}$ SERGIO A. LAMBERTUCCI, ${ }^{3}$ \\ GUILLERMO WIEMEYER, ${ }^{4,5}$ JOSÉ A. SANCHEZ-ZAPATA, ${ }^{6}$ FERNANDO HIRALDO ${ }^{7}$ \& JOSÉ A. DONÁZAR ${ }^{7}$ \\ ${ }^{1}$ Department of Evolutionary Ecology, National Museum of Natural History (CSIC), Madrid, Spain \\ ${ }^{2}$ Food Phytochemistry Department, Instituto de la Grasa (CSIC), Seville, Spain \\ ${ }^{3}$ Laboratorio Ecotono-INIBIOMA (CONICET-Universidad Nacional del Comahue), Bariloche, Argentina \\ ${ }^{4}$ Jardín Zoológico de la Ciudad de Buenos Aires, Buenos Aires, Argentina \\ ${ }^{5}$ The Peregrine Fund, Boise, ID, USA \\ ${ }^{6}$ Department of Applied Biology, University Miguel Hernández, Orihuela, Spain \\ ${ }^{7}$ Department of Conservation Biology, Estación Biológica de Doñana (CSIC), Seville, Spain
}

Because large species ingest proportionally less food than small ones, it may be predicted that they should incorporate relatively fewer carotenoids to a proportionally equal volume of blood. However, some species may increase their levels of circulating carotenoids by ingesting unusual food. We tested whether the plasma concentration of carotenoids scales to the three-quarter power of mass in nine predatory and scavenger raptor species. No significant allometric relationships were found due to the unusually high concentrations of carotenoids in the Egyptian Vulture Neophron percnopterus and the Andean condor Vultur gryphus. To assess whether these two species deviate from the allometric rule through the exploitation of unusual sources of carotenoids, or due to a physiological adaptation to improve the uptake of carotenoids, we determined allometric patterns in individuals of these two species kept in captivity with an exclusive diet of flesh. Our results provided support for the allometric rule because the slope of the allometric equation did not differ from a three-quarter exponent when carotenoid levels of the two outliers were replaced by those of captive birds. This adjustment to the allometric rule suggests a lack of any physiological adaptation to improve the uptake of the low concentrations of carotenoids contained in flesh. Differences between species in carotenoid incorporation into the bloodstream may be ultimately due to contrasting evolutionary history, physiology and associated colour-signalling strategies, but proximately due to the acquisition of these micronutrients from both usual and unusual dietary sources.

Keywords: body mass, carnivores, diet, micronutrients, unusual food.

Body size has a pervasive role in many metabolic and biochemical processes, as described by allometries and scaling relationships approximating quarter powers of mass (Peters 1983, Calder 1984, Schmidt-Nielsen 1984, West \& Brown 2005). Several recent comparative studies have concluded that a single scaling exponent does not exist (Makarieva et al. 2008) but that the theoretical predictions for average scaling exponents approaching a

*Corresponding author.

Email: g.blanco@csic.es mean slope of 3/4 were well supported as speciesaveraged basal rates (Isaac \& Carbone 2010). Deviations from the basic size-dependent allometric pattern have been argued to be due to variations in environmental conditions such as temperature and availability of resources (McNabb 2002, Glazier 2005, Makarieva et al. 2008), as well as to species-specific physiological, morphological and behavioural adaptations and innovations subjected to selection (Calder 1984, Schmidt-Nielsen 1984, $\mathrm{McNabb}$ 2002). Allometric quarter power laws of metabolism often imply that the pools of dietary 
nutrients scale allometrically with body mass, whereas deviations from the rule can be conceived as disequilibria between supply and demand for particular nutrients (Peters 1983, Banavar et al. 2002).

Optimal foraging theory predicts that animals minimize costs and maximize food intake, which in top carnivores was traditionally assumed equivalent to maximizing energy intake (Stephens \& Krebs 1986). Also, traditionally it has been claimed that animals do not simply maximize the rate of net energy intake but also seek specific nutrients and avoid toxins (Belovsky 1978, 1990, Bozinovic \& Martinez del Rio 1996). It is known that top carnivores are able to select food based on its quality in terms of, for example, mean energy density of prey (e.g. Spitz et al. 2012). However, there is little information on the role that diet selection aimed at searching for specific nutrients, such as carotenoids, may play in constraining optimal foraging of animals (Catoni et al. 2011), especially in top carnivores feeding on flesh that is generally limited in these micronutrients (Goodwin 1984, Negro et al. 2002).

Carotenoids are obtained by animals exclusively from food, so diet composition plays a primary role in interspecific variability in carotenoid acquisition in birds (Tella et al. 2004, McGraw \& Hill 2006, Cohen et al. 2008, 2009). Previous studies have shown that large bird species incorporate relatively fewer carotenoids to a proportionally equal volume of blood (Tella et al. 2004, McGraw 2005) but this relationship should be modulated by the potentially variable uptake and physiological demand of these micronutrients for health and colouration (Tella et al. 2004, McGraw \& Hill 2006, Hill \& Johnson 2012). Strikingly, closely related species of a similar size and diet may differ greatly in their circulating carotenoid concentrations because of potentially different levels of efficiency in carotenoid absorption, which may be linked to different physiological demands, e.g. for colouration, rather than supply (Tella et al. 2004, McGraw 2005, McGraw \& Hill 2006). In addition, species with similar diets may differentially seek supplementary carotenoids by exploiting unusual food sources. This strategy can promote greater carotenoid ingestion with or without any physiological adaptation to improve the uptake of carotenoids in the intestine (McGraw \& Hill 2006). Distinguishing between these alternatives requires a detailed knowledge of the concentration of carotenoids in different dietary sources, especially by establishing the amount of carotenoids obtained from the typical, albeit often highly variable, diet vs. that obtained from unusual food sources, which is challenging (Negro et al. 2000, 2002, Tella et al. 2004, Cohen et al. 2008, 2009). Allometries and scaling relationships can contribute to identifying residual variation in the assimilation of micronutrients, including pigments, due to factors other than mass in order to elucidate general patterns and propose new hypotheses, even in species whose diet may be unknown.

We assessed whether the plasma concentration of carotenoids scales to the three-quarter power of mass in predatory and scavenger raptors of the closely related Accipitrinidae and Cathartidae families (Hackett et al. 2008). This group of species is well suited to evaluate this relationship because their typical, relatively homogeneous, diet of vertebrate flesh (del Hoyo et al. 1992) presumably provides similarly low carotenoid levels (Goodwin 1984, Negro et al. 2002). Thus, using this subset of species we were able, to some extent, to control for the potential phylogenetic constraints explaining a substantial amount of the variability in diet-based carotenoid concentrations found in interspecific studies (Tella et al. 2004, Cohen et al. 2008, 2009). This approach allows the identification of species that deviate from the presumed general allometric pattern due to additional, generally unknown factors.

We hypothesized that residual deviation from the allometric rule may arise through feeding adaptations and innovations as a response to potential disequilibria between constantly low ingestion of carotenoids from flesh and a high demand for these micronutrients and pigments, e.g. for colouration. We specifically focused on species known for complementing their typical diet with unusual food, namely herbivore excrement in the Egyptian Vulture Neophron percnopterus (Negro et al. 2002) and vegetal matter in the Andean Condor Vultur gryphus (Blanco et al. 2013). These feeding habits could potentially increase the incorporation of carotenoids into the bloodstream at concentrations higher than expected given their respective body size; consequently, these species should not conform to the tested allometric rule. To further assess the influence of these unusual foods on carotenoid uptake, we also determined allometric patterns considering individuals of these two species kept in captivity 
and fed on an exclusive diet of flesh, without vegetal content, from fresh muscular tissue with bones and skin from laboratory animals and herbivore livestock mammals, mostly cattle and goats (Negro et al. 2002, Blanco et al. 2013). Therefore, the ingestion of viscera and vegetation was likely to have been the most important difference in diet between captive and wild individuals. Thus, we tested whether wild top avian carnivores deviate from the allometric rule through the exploitation of unusual sources of carotenoids or, alternatively, due to a physiological adaptation to improve the uptake of carotenoids from their typical diet of flesh.

\section{METHODS}

We reviewed published studies that reported plasma carotenoid concentrations in wild adult accipitrinid and cathartid raptors (Table 1; plasma carotenoid concentrations measured in captive adults of two species were also drawn from the literature) to test the general model of allometric scaling, $y=a M^{b}$, in which the concentration of plasma carotenoids $(y$, expressed as $\mu \mathrm{g} / \mathrm{mL})$ is a non-linear function of the adult mass $(M$, expressed in grams), and the constant $a$ and the scaling exponent $b$ are empirically determined. The scaling exponent $b$ is expected to follow the theoretical predictions of 0.75 (West \& Brown 2005). Fitting a line to a bivariate dataset can be deceptively complex, and there has been much debate on this issue in the literature (Warton et al. 2006). The empirical analysis of allometric scaling is traditionally calculated by exponentiating the equation for a straight line fitted to logarithmic transformations of the original bivariate data. However, this method may not be well suited for fitting statistical models to data expressed in the arithmetic scale (Packard 2013), which could produce inexact estimates for parameters in the allometric equation (Packard 2013, and references therein). This limitation is unrelated to the linear regression model selected, which could be either a reduced major axis (RMA) or an ordinary least squares (OLS). Although each model type may be acceptable (Kaitaniemi 2004), it is advisable to determine both parameters with untransformed data (Kaitaniemi 2004, Packard 2013). Therefore, we used three regression methods commonly used

Table 1. Mean ( $\pm 1 \mathrm{sd})$ concentration of total plasma carotenoid $(\mu \mathrm{g} / \mathrm{mL})$, sample size $(n)$, average body mass $(\mathrm{g})$, foraging habits, diet and carotenoid-dependent colouration of wild accipitrinid and cathartid raptors.

\begin{tabular}{|c|c|c|c|c|c|c|}
\hline \multirow[b]{2}{*}{ Species } & \multirow[b]{2}{*}{$\begin{array}{l}\text { Foraging habits } \\
{\text { (diet) })^{\mathrm{a}}}\end{array}$} & \multirow[b]{2}{*}{$\begin{array}{l}\text { Carotenoid } \\
\text { colouration }^{a}\end{array}$} & \multirow[b]{2}{*}{$\begin{array}{l}\text { Body } \\
\text { mass }^{a}\end{array}$} & \multicolumn{2}{|c|}{ Carotenoid concentration } & \multirow[b]{2}{*}{ References } \\
\hline & & & & Natural diet (wild) & $\begin{array}{l}\text { Flesh diet } \\
\text { (captivity) }\end{array}$ & \\
\hline Cathartes aura & $\begin{array}{l}\text { S, OP (vertebrates, } \\
\text { invertebrates }{ }^{\mathrm{b}} \text { ) }\end{array}$ & No & 1467 & $1.82 \pm 1.18, n=11$ & & Tella et al. (2004) \\
\hline Coragyps atratus & $\begin{array}{l}\text { S, OP (vertebrates, } \\
\left.\text { invertebrates }{ }^{b}\right)\end{array}$ & No & 1500 & $1.99 \pm 0.84, n=17$ & & Blanco et al. (2013) \\
\hline Vultur gryphus & OS (mammals) & $\begin{array}{l}\text { Iris, tongue, head } \\
\text { and neck skin }\end{array}$ & 13000 & $5.19 \pm 2.06, n=22$ & $\begin{array}{l}0.30 \pm 0.45 \\
n=27\end{array}$ & Blanco et al. (2013) \\
\hline Milvus migrans & $\begin{array}{l}\mathrm{P}, \mathrm{FS} \text { (vertebrates, } \\
\text { invertebrates }^{\mathrm{b}} \text { ) }\end{array}$ & Ceres and legs & 754 & $4.44 \pm 3.40, n=127$ & & Blas et al. (2013) \\
\hline $\begin{array}{l}\text { Neophron } \\
\text { percnopterus }\end{array}$ & $\mathrm{S}$, OP (vertebrates) & Facial skin & $2105^{c}$ & $6.5 \pm 5.29, n=196$ & $\begin{array}{l}0.49 \pm 0.44 \\
n=4\end{array}$ & Negro et al. (2002) \\
\hline Gyps fulvus & OS (vertebrates) & No & 7436 & $1.02 \pm 0.66, n=5$ & & Tella et al. (2004) \\
\hline $\begin{array}{l}\text { Aegypius } \\
\text { monachus }\end{array}$ & S, OP (vertebrates) & No & 9625 & $0.47 \pm 0.26, n=15$ & & Tella et al. (2004) \\
\hline Accipiter nisus & P (birds) & Iris, ceres and legs & 237 & $8.57, n=1$ & & Tella et al. (2004) \\
\hline $\begin{array}{l}\text { Parabuteo } \\
\text { unicinctus }\end{array}$ & $\mathrm{P}$ (vertebrates) & Ceres and legs & 886 & $6.29 \pm 5.62, n=2$ & & Tella et al. (2004) \\
\hline
\end{tabular}

Data on captive Egyptian Vultures Neophron percnopterus and Andean Condors Vultur gryphus with a controlled diet of flesh in captivity are included. Concentrations of total plasma carotenoids in wild and captive birds are from published sources. Foraging habits: FS, facultative scavenger; OP, occasional predator; OS, obligate scavenger; P, predator; S, scavenger. 'a Source: del Hoyo et al. (1992); Tella et al. (2004). ' Occasionally. 'Body mass was calculated by including data from the heavier Canary Island subspecies majorensis (Donázar et al. 2002). 
in allometry for estimating the values of $a$ and $b$ : an OLS regression, a linear RMA regression and a non-linear regression (NLR). Data were logtransformed in OLS and RMA.

Allometric studies often use skewed data for body mass (many small species and few large species). The influence of those few large species on the allometric scaling is typically reduced when the data are expressed in logarithmic form but it remains worth testing for outliers with a statistical approach. The possibility of adjusting inaccurate models may be determined by re-running the analyses without the outliers. Outliers can be detected by calculating the Mahalanobis distance, $D$, for each observation. This distance is a measure of the statistical distance between each observation and the centroid. A squared Mahalanobis distance (Hotelling's $T^{2}$ ) may be calculated for each observation while holding the observation out of the sample (Vargas 2003, Bersimis et al. 2007). This prevents potential outliers from distorting the very detection of outliers. We calculated $T^{2}$ to identify outliers from upper control limits (UCL, i.e. Jayakumar \& Thomas 2013) in the correlation structure between plasma carotenoids and body mass. Concentrations of plasma carotenoids measured in wild species with $T^{2}>$ UCL were replaced by the values measured in captive birds with a controlled diet of flesh. This replacement aimed to evaluate outliers not only based on their number but also with respect to their correct positions (Shabbak \& Midi 2012). The replacement process was carried out step by step starting with the species with the highest $T^{2}$. The $T^{2}$ values were recalculated after each substitution. The process ended when all $T^{2}<$ UCL. The regressions were recalculated after replacing the outlier species, and the new values of the exponent were confronted with the value 0.75 .

We compared the resulting three parameterizations with two indices of model fit previously applied to test the allometric scaling laws (Kaitaniemi 2004): Akaike's information criterion (AIC) and the coefficient of determination $r^{2}$. The former describes the likelihood that the data fit a specific model and the latter states the proportion of variation in the concentration of plasma carotenoids that can be explained by the regression equation (Kaitaniemi 2004). Predicted and observed values were correlated to obtain $r^{2}$ in each parameterization. The predicted values were regressed against the observed values with no intercept term to obtain AIC for each fit (Kaitaniemi 2004).
The 95\% confidence limits for the scaling exponent $\alpha$ were calculated to check whether they included the 0.75 value in each fit. The scaling exponents were also tested against the 0.75 value with the Student $t$-test (OLS and NLR) or the sample correlation coefficient $r$ between residuals and fitted values (RMA). All analyses were made in the JMP statistical analysis software (SAS Institute 2009).

\section{RESULTS}

The scaling exponent was not significant in any regression calculated with plasma carotenoid concentration data from wild birds (OLS: -0.442 , 95\% CI -0.97, +0.09, NLR: $-0.383,95 \%$ CI -0.77 , +0.01, RMA: $-0.742,95 \%$ CI -1.10 , +0.22 ; Supporting Information Fig. Sla-c). Visual inspection of the OLS regression (Fig. la) suggested that the wild Andean Condor and the Egyptian Vulture would be tagged as outliers (see also Fig. S1 for the other models). Outlier analysis corroborated the carotenoid value of the wild Andean Condor as the first outlier $\left(T^{2}=5.08\right.$, $\mathrm{UCL}=4.49$ ) and the carotenoid value of the Egyptian Vulture as a second outlier $\left(T^{2}=4.66\right.$, $\mathrm{UCL}=4.49$ ). When carotenoid concentrations measured in wild birds of the outlier species were replaced by measures of captive birds with a controlled diet of flesh, the slope of the allometric equation did not differ from a three-quarter exponent in any of the three regression models (Table 2, Figs $1 \mathrm{~b}$ and Sld-f).

\section{DISCUSSION}

The allometric relationship between metabolic rate and body mass suggests that large bird species should incorporate relatively fewer carotenoids per blood volume than small ones (Tella et al. 2004, McGraw \& Hill 2006, Cohen et al. 2009). We found that the decrease in plasma carotenoids with the increase in body size in a sample of wild raptor species was non-linear and deviated from the allometric scaling law between physiological traits and a 0.75 -power of mass (West \& Brown 2005). This deviation was due to the influence of two outliers corresponding to a medium-sized accipitrinid vulture (Egyptian Vulture) and the largest cathartid vulture (Andean Condor).

As predicted, the Egyptian Vulture did not conform to the allometric rule when foraging on a 
(a)

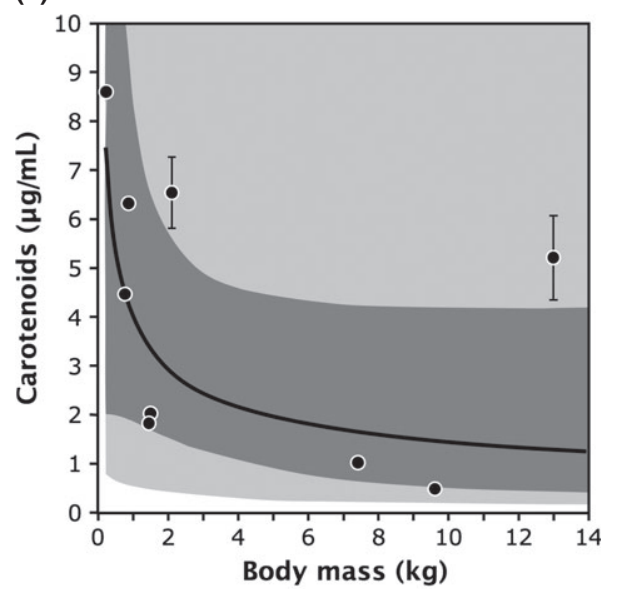

(b)

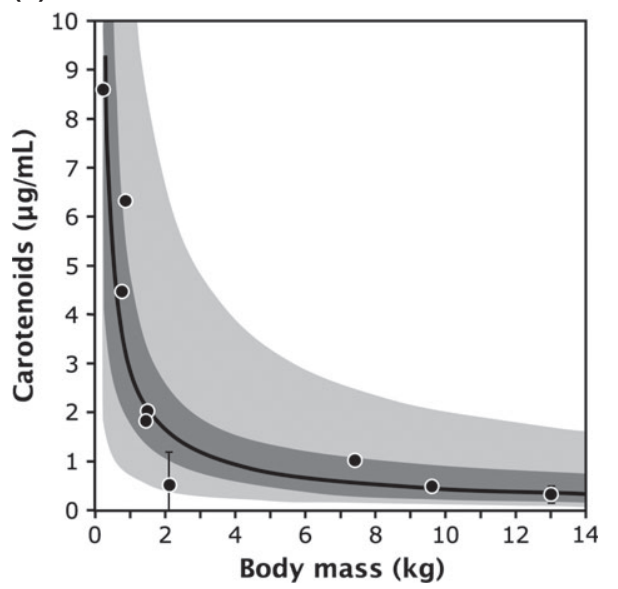

Figure 1. Plasma carotenoid concentration and body mass of raptors of the families Accipitrinidae and Cathartidae. The allometric relationship was not significant when carotenoids were measured in wild individuals of all species (a) but it was significant when carotenoid concentration was measured in captive instead of wild Egyptian Vultures and Andean Condors (b), which were fed on a controlled diet of flesh. Left and right symbols with the $\pm 95 \% \mathrm{Cl}$ correspond to Egyptian Vultures and Andean Condors, respectively. The line shows the backlog transformed OLS regression of carotenoid concentration and body mass. Light and dark shaded areas represent the $95 \% \mathrm{Cl}$ of the line and the data points of the regression, respectively (see other regression lines in Fig. S1).

natural diet in the wild. When diet was restricted to flesh in captivity, the circulating concentration of carotenoids was about 13 times lower than in the wild (Negro et al. 2002), and then adjusted to the allometric rule. Similarly, the Andean Condor adjusted to the allometric relationship when diet was restricted to flesh in captivity but not when foraging on a natural diet including entire carcasses and other matter in the wild. Thus, despite being the heaviest raptor species, wild Andean Condors showed much higher carotenoid concentrations compared with smaller obligate scavengers (Negro et al. 2002, Tella et al. 2004), and even showed higher concentrations than predatory and facultative scavenger raptors occasionally feeding on insects (e.g. Black Kites Milvus migrans, Blas et al. 2013), an important source of carotenoids (Goodwin 1984). The Egyptian Vulture has been argued to require a higher supply of lutein than that provided by carrion due to a potentially elevated need for this pigment for facial skin colouration and health (Negro et al. 2002). The lack of adjustment of wild Andean Condors to the tested allometric rule may arise due to a similar disequilibrium between supply and demand for carotenoids used as pigments and micronutrients. This deviation from the size-dependent allometric rule further supports the hypothesis that the Andean Condor may exploit vegetal matter as a potential dietary source of carotenoids, by ingesting both natural fresh vegetation and vegetal content of herbivore carcasses (Blanco et al. 2013).

We assumed that carotenoid levels of captive individuals were not strongly affected by factors associated with captivity other than controlled diet or, if affected, these levels would decrease proportional to species body mass. This assumption was supported by the fact that circulating concentrations of carotenoids in captive Egyptian Vultures fed with flesh rapidly increased with the ingestion of herbivore excrement (Negro et al. 2002). This also agrees with the primary role of diet on carotenoid levels (Tella et al. 2004, McGraw \& Hill 2006, Cohen et al. 2008, 2009), which has been extensively confirmed by the increase of circulating carotenoids after experimental food enrichment with these pigments in captivity (McGraw \& Hill 2006). In addition, because the smallest species considered here showed higher carotenoid levels, and because they display carotenoid-based ornaments, they could also have specific adaptations to increase dietary carotenoid intake. Determining whether this potential adaptation is dependent on body size poses analytical difficulties because among the smallest raptors of the considered families (especially Accipitrinidae), most species have shown carotenoid-dependent colouration in the ceres, legs and/or iris (del Hoyo et al. 1992). Alternatively, specific adaptations for carotenoid intake could have evolved to counteract limits imposed by the body mass of larger species, whereas 
Table 2. Comparison of statistical models fitted to plasma carotenoids as a function of body mass in nine raptor species.

\begin{tabular}{|c|c|c|c|c|c|c|c|}
\hline \multirow[b]{2}{*}{ Regression } & \multirow[b]{2}{*}{ Predictive equation } & \multicolumn{3}{|c|}{ Model } & \multicolumn{3}{|c|}{ Slope } \\
\hline & & $\mathrm{AIC}$ & $\triangle \mathrm{AIC}$ & $r^{2}$ & $\mathrm{Cl} 95 \%$ & Test & $P$ \\
\hline Linear OLS & $\hat{y}=814.40 x^{-0.818}$ & 30.93 & 5.2 & 0.74 & $-1.18,-0.46$ & 0.45 & 0.666 \\
\hline Non-linear & $\hat{y}=378.17 x^{-0.683}$ & 32.36 & 6.6 & 0.85 & $-1.03,-0.42$ & 0.51 & 0.619 \\
\hline Linear RMA & $\hat{y}=1688.75 x^{-0.914}$ & 25.77 & 0.0 & 0.94 & $-1.34,-0.62$ & 0.41 & 0.272 \\
\hline
\end{tabular}

Models were calculated with the plasma carotenoid concentration sampled in captive Andean Condors and captive Egyptian Vultures (see Results and Fig. S1 for the models including only wild birds). Predictive equations are shown with back-log transformed constants in OLS and RMA regressions, in addition to the goodness-of-fit determined with the Akaike's information criterion (AIC, $\triangle \mathrm{AIC}$ ) and the coefficient of determination $r^{2}$ (Kaitaniemi, 2004). Upper and lower confidence intervals of slopes (CI 95\%) are shown, with the test of the slope against the $H_{0}: b=-0.75$. The slope test was calculated with the Student $t$-test (OLS and NLR regressions) or with the sample correlation $r$ coefficient between residuals and fitted values (RMA regression).

smaller species could acquire the lower, sizedependent, required carotenoid levels by selectively foraging on carotenoid-rich food such as insects (del Hoyo et al. 1992). Therefore, we suggest that the allometric deviations of plasma carotenoids in raptor species could be a meaningful phenomenon and not a random result due to the small sample size of species. Additional data on carotenoid levels of small raptors and further studies with other taxa would clarify this.

The adjustment to the allometric rule of captive Egyptian Vultures and Andean Condors suggests a lack of any physiological adaptation to improve the uptake of the low concentrations of carotenoids contained in flesh. However, whether feeding innovations of these species imply physiological adaptations for the increased assimilation of carotenoids from vegetal matter, or whether this is a simple function of the state or consumed amount of this and other unusual food sources, requires further research. In addition, interspecific differences in plasma carotenoid concentrations may be related to differences in the selective absorption processes of the different kinds of carotenoids in the small intestine (McGraw 2005, McGraw \& Hill 2006), or their differential transformation into vitamin A (Hill \& Johnson 2012). Whatever the case, the unexpectedly high concentration of carotenoids in the Andean Condor, the largest obligate scavenger, suggests increased carotenoid requirements for deposition in the integument or for other physiological functions. Contrary to the other species considered here, which show carotenoid-dependent colouration only in the ceres and legs, or no carotenoid colouration at all, the Andean Condors' appearance suggests carotenoid deposition in the tongue, iris and bare skin in the neck and head, including the comb and wattles in males, in which the colour intensifies by means of a flushing display (Blanco et al. 2013). We predict that other large cathartid vultures with presumably carotenoidbased colouration, especially the King Vulture Sarcoramphus papa and the California Condor Gymnogyps californianus, should show elevated carotenoid concentrations for their size, associated with unknown unusual dietary sources. In addition, the usual exploitation of palm fruits presumably rich in carotenoids should be linked to increased levels of carotenoids in the accipitrinid Palm-nut Vulture Gypohierax angolensis (del Hoyo et al. 1992). The occasional 'frugivory' of other raptor species (Galetti \& Guimarães 2004 and references therein) suggests that carotenoids and other micronutrients may be actively sought after as dietary supplements by top carnivores, and requires further research for its implications in their physiology, ecology and conservation.

Research on allometries and scaling relationships is rapidly expanding in a search for ecological laws (Sibly et al. 2012). Body size is generally used as an explanatory factor or as a proxy for other traits that are the true causes of these relationships (Raerinne 2013), for instance the uptake in the bloodstream of carotenoids in the present study. This implies that allometry and scaling relationships may primarily depend on metabolism and physiology related to size, but also that these relationships can be modulated by other factors, e.g. behavioural adaptations and innovations to cope with social and environmental variations. Additional factors and caveats can lead to insufficient or misleading causal explanations and exceptions to the general scaling and allometric pattern, thus 
requiring further research on the underlying mechanisms (Stumpf \& Porter 2012, Raerinne 2013). Therefore, in addition to their predictive and explanatory value, scaling and allometric relationships, when conceived heuristically, hold great research potential in their ability to shed light on the generally unknown underlying mechanisms (Raerinne 2013). This approach gives a special relevance to residual variation and adaptive deviations' in the form of outliers from the general pattern (Calder 1984, McNabb 2002), which are prone to experimentation (e.g. diet manipulation), in order to elucidate connections between variables, describe phenomena and suggest new hypotheses (Raerinne 2013).

In conclusion, this study suggests that betweenspecies differences in carotenoid incorporation into the bloodstream may be ultimately due to contrasting evolutionary history, physiology and associated colour-signalling strategies of top avian carnivores, but proximately due to the acquisition of these micronutrients from usual and, importantly, unusual dietary sources. Scaling and allometric relationships can be successfully used to detect species that exploit unusual food and other matter as a source of carotenoids and other micronutrients, contributing to the understanding of the mechanisms underlying optimal foraging. We suggest that any trait subjected to scaling and allometry could be treated with a heuristic approach similar to that used here to reveal possible statistical deviations potentially linked to specific adaptations.

This work was funded by Fundación Banco Bilbao Vizcaya Argentaria project BIOCON-08-126 and project CGL2009-12753-C02-01 from the Spanish Ministerio de Economía y Competitividad. D.H.M. is a member of the IBERCAROT Network financed by CYTED (ref. 112RT0445). We acknowledge the efforts of the reviewers in helping us improve the paper's content and style.

\section{REFERENCES}

Banavar, J.R., Damuth, J., Maritan, A. \& Rinaldo, A. 2002. Supply-demand balance and metabolic scaling. Proc. Natl Acad. Sci. USA 99: 10506-10509.

Belovsky, G.E. 1978. Diet optimization in a generalist herbivore: the moose. Theor. Pop. Biol. 14: 105-134.

Belovsky, G.E. 1990. How important are nutrient constraints in optimal foraging models or are spatial/temporal factors more important? In Hughes, R.N. (ed.) Behavioural Mechanisms of Food Selection. Berlin: Springer-Verlag.
Bersimis, S., Psarakis, S. \& Panaretos, J. 2007. Multivariate statistical process control charts: an overview. Qual. Rel. Eng. Int. 23: 517-543.

Blanco, G., Hornero-Mendez, D., Lambertucci, S.A., Bautista, L.M., Wiemeyer, G., Sanchez-Zapata, J.A., Garrido-Fernandez, J., Hiraldo, F. \& Donazar, J.A. 2013. Need and seek for dietary micronutrients: endogenous regulation, external signalling and food sources of carotenoids in New World vultures. PLoS One 8: e65562.

Blas, J., Cabezas, S., Figuerola, J., López, L., Tanferna, A., Hiraldo, F., Sergio, F. \& Negro, J.J. 2013. Carotenoids and skin coloration in a social raptor. J. Raptor Res. 47: 174-184.

Bozinovic, F. \& Martinez del Rio, C. 1996. Animals eat what they should not: why do they reject our foraging models? Rev. Chil. Hist. Nat. 69: 15-20.

Calder, W.A. 1984. Size, Function and Life History. Cambridge, MA: Harvard University Press.

Catoni, C., Metzger, B., Schaefer, H.M. \& Bairlein, F. 2011. Garden Warbler, Sylvia borin, detect carotenoids in food but differ strongly in individual food choice. J. Ornithol. 152 153-159.

Cohen, A.A., McGraw, K.J., Wiersma, P., Williams, J.B., Robinson, W.D., Robinson, T.R., Brawn, J.D. \& Ricklefs, R.E. 2008. Interspecific associations between circulating antioxidant levels and life-history variation in birds. $\mathrm{Am}$. Nat. 172: 178-193.

Cohen, A.A., McGraw, K.J. \& Robinson, W.D. 2009. Serum antioxidant levels in wild birds vary in relation to diet, season, life history strategy, and species. Oecologia 161: 673-683.

Donázar, J.A., Negro, J.J., Palacios, C.J., Gangoso, L., Godoy, J.A., Ceballos, O. \& Hiraldo, F. 2002. Description of a new subspecies of the Egyptian Vulture (Accipitridae: Neophron percnopterus) from the Canary Islands. J. Raptor Res. 36: 17-23.

Galetti, M. \& Guimarães, P.R. Jr 2004. Seed dispersal of Attalea phalerata (Palmae) by Crested Caracaras (Caracara plancus) in the Pantanal and a review of frugivory by raptors. Ararajuba 12: 133-135.

Glazier, D.S. 2005. Beyond the '3/4-power law': variation in the intra- and interspecific scaling of metabolic rate in animals. Biol. Rev. 80: 611-662.

Goodwin, T.W. 1984. The Biochemistry of the Carotenoids, Vol. 2. New York: Chapman \& Hall.

Hackett, S.J., Kimball, R.T., Reddy, S., Bowie, R.C.K., Braun, E.L., Braun, M.J., Chojnowski, J.L., Cox, W.A., Han, K.L., Harshman, J., Huddleston, C.J., Marks, B.D., Miglia, K.J., Moore, W.S., Sheldon, F.H., Steadman, D.W., Witt, C.C. \& Yuri, T. 2008. A phylogenomic study of birds reveals their evolutionary history. Science 320: 1763 1768.

Hill, G.E. \& Johnson, J.D. 2012. The vitamin A-redox hypothesis: a biochemical basis for honest signaling via carotenoid pigmentation. Am. Nat. 180: E127-E150.

del Hoyo, J., Elliott, A., Sargatal, J. \& Cabot, J. (eds) 1992. Handbook of the Birds of the World, Vol. 2. Barcelona: Lynx Edicions.

Isaac, N.J.B. \& Carbone, C. 2010. Why are metabolic scaling exponents so controversial? Quantifying variance and testing hypotheses. Ecol. Lett. 13: 728-735. 
Jayakumar, G.D.S. \& Thomas, B.J. 2013. A new procedure of clustering based on multivariate outlier detection. J. Data Sci. 11: 69-84.

Kaitaniemi, P. 2004. Testing the allometric scaling laws. J. Theor. Biol. 228: 149-153.

Makarieva, A.M., Gorshkov, V.G., Li, B.L., Chown, S.L., Reich, P.B. \& Gavrilov, V.M. 2008. Mean mass-specific metabolic rates are strikingly similar across life's major domains: evidence for life's metabolic optimum. Proc. Natl Acad. Sci. USA 105: 16994-16999.

McGraw, K.J. 2005. Interspecific variation in dietary carotenoid assimilation in birds: links to phylogeny and color ornamentation. Comp. Biochem. Physiol. B 142: 245-250.

McGraw, K.J. \& Hill, G. 2006. Mechanics of carotenoid-based coloration in birds. In Hill, G.E. \& McGraw, K.J. (eds) Bird Coloration I: Mechanisms and Measurements. Cambridge, MA: Harvard University Press.

McNabb, B.K. 2002. The Physiological Ecology of Vertebrates: A View from Energetics. Ithaca, NY: Cornell University Press.

Negro, J.J., Tella, J.L., Blanco, G., Forero, M.G. \& GarridoFernandez, J. 2000. Diet explains interpopulation variation of plasma carotenoids and skin pigmentation in nestling white storks. Physiol. Biochem. Zool. 73: 97-101.

Negro, J.J., Grande, J.M., Tella, J.L., Garrido, J., Hornero, D., Donazar, J.A., Sanchez-Zapata, J.A., Benitez, J.R. \& Barcell, M. 2002. Coprophagy: an unusual source of essential carotenoids. Nature 416: 807-808.

Packard, G.C. 2013. Is logarithmic transformation necessary in allometry? Biol. J. Linn. Soc. 109: 476-486.

Peters, R.H. 1983. The Ecological Implications of Body Size. Cambridge: Cambridge University Press.

Raerinne, J.P. 2013. Explanatory, predictive, and heuristic roles of allometries and scaling relationships. Bioscience $\mathbf{6 3}$ : 191-198.

SAS Institute 2009. JMP v. 8.0. Cary, NC: SAS Institute.

Schmidt-Nielsen, K. 1984. Scaling: Why is Animal Size so Important? Cambridge: Cambridge University Press.

Shabbak, A. \& Midi, H. 2012. An improvement of the Hotelling T-2 statistic in monitoring multivariate quality characteristics. Math. Prob. Eng. 2012: 1-15.

Sibly, R.M., Brown, J.H. \& Kodric-Brown, A. 2012. Metabolic Ecology: A Scaling Approach. Oxford: Wiley-Blackwell.
Spitz, J., Trites, A.W., Becquet, V., Brind'Amour, A., Cherel, Y., Galois, R. \& Ridoux, V. 2012. Cost of living dictates what whales, dolphins and porpoises eat: the importance of prey quality on predator foraging strategies. PLoS One 7: e50096.

Stephens, D.W. \& Krebs, J.R. 1986. Foraging Theory. Princeton, NJ: Princeton University Press.

Stumpf, M.P.H. \& Porter, M.A. 2012. Critical truths about power laws. Science 335: 665-666.

Tella, J.L., Figuerola, J., Negro, J.J., Blanco, G., RodriguezEstrella, R., Forero, M.G., Blazquez, M.C., Green, A.J. \& Hiraldo, F. 2004. Ecological, morphological and phylogenetic correlates of interspecific variation in plasma carotenoid concentration in birds. J. Evol. Biol. 17: 156-164.

Vargas, N.J.A. 2003. Robust estimation in multivariate control charts for individual observations. J. Quality Tech. 35: 367376.

Warton, D.I., Wright, I.J., Falster, D.S. \& Westoby, M. 2006. Bivariate line-fitting methods for allometry. Biol. Rev. 81: 259-291.

West, G.B. \& Brown, J.H. 2005. The origin of allometric scaling laws in biology from genomes to ecosystems: towards a quantitative unifying theory of biological structure and organization. J. Exp. Biol. 208: 1575-1592.

Received 30 September 2013; revision accepted 9 March 2014. Associate Editor: Dan Chamberlain.

\section{SUPPORTING INFORMATION}

Additional Supporting Information may be found in the online version of this article:

Figure S1. Regression lines of OLS, NRL and RMA models calculated on data of wild raptor species (a, b and c) and data replacing the two outlier species (Egyptian Vulture and Andean condor, left and right points respectively) with data on these species when fed with a controlled diet of flesh in captivity (d, e and f). 


\section{SUPPORTING INFORMATION}

Figure S1. Regression lines of OLS, NRL and RMA models calculated on data of wild raptor species (a, b and c) and data replacing the two outlier species (Egyptian vulture and Andean condor, left and right points respectively) with data on these species when fed with a controlled diet of flesh in captivity (d, e and f). The slopes calculated with plasma carotenoid concentrations sampled in wild birds ( $a, b$, and $c)$ were not significant (see results).
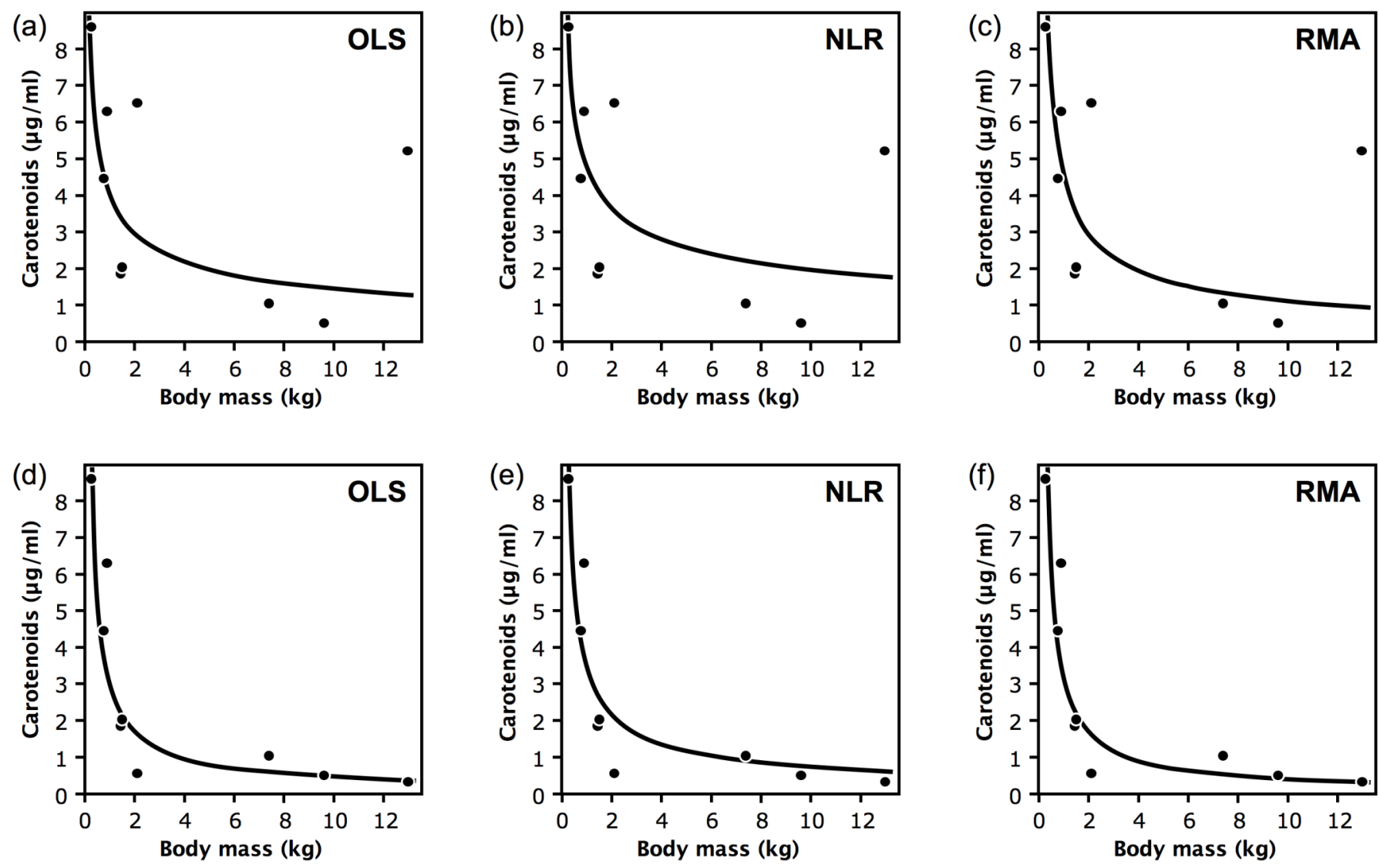